RIMCIS

International and Multidisciplinary Journal of Social Sciences

\section{Hipatia Press}

www.hipatiapress.com

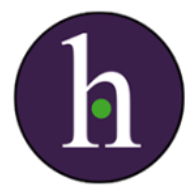

Instructions for authors, subscriptions and further details:

http://rimcis.hipatiapress.com

\title{
The Concept Of Human2Human In The Response To COVID-19
}

Fernando Almeida1

1) University of Porto, INESC TEC \& ISPGAYA, Portugal

Date of publication: article first published online June, 2 2020; Issue published July, 302020.

Edition period: July 2020 - November 2020

To cite this article: Almeida, F. (2020). The Concept Of Human2Human In The Response To COVID-19. International and Multidisciplinary Journal of Social Sciences, 9(2), 129-151. doi: 10.17583/rimcis.2020.5524

To link this article: http://doi.org/10.17583/rimcis.2020.5524

\section{PLEASE SCROLL DOWN FOR ARTICLE}

The terms and conditions of use are related to the Open Journal System and to Creative Commons Attribution License (CC-BY). 


\section{The Concept Of Human2Human In The Response To COVID-19}

Fernando Almeida

University of Porto

\section{Abstract}

Civil society, business, and local authorities in Portugal have come together to seek solutions to the challenges posed by COVID-19. This study intends to explore the relevance of these initiatives for the implementation of the Human2Human paradigm through five case studies. This approach allows us to understand how these initiatives are organized, to identify the convergent and divergent points between them, and to explore the role of information and communication technologies in these projects. The results of this study enabled the identification of a set of diversified projects with high impact for professionals who are in the front line in the fight against COVID-19 and for the most vulnerable population, particularly the elderly. This study is especially relevant from a practical point of view by exploring the relevance of these initiatives, by highlighting the need for collaborative work and in multidisciplinary teams, and by encouraging their replication to other countries.

Keywords: Human2Human, volunteering, knowledge society, technology, COVID-19 


\section{El Concepto De \\ Humano2Humano En La \\ Respuesta A Covid-19}

Fernando Almeida

University of Porto

\section{Resumen}

La sociedad civil, las empresas y las autoridades locales de Portugal se han unido para buscar soluciones a los desafíos que plantea COVID-19. El presente estudio tiene por objetivo explorar la pertinencia de esas iniciativas para la aplicación del paradigma Humano2Humano mediante cinco estudios de casos. Este enfoque permite comprender la organización de estas iniciativas, identificar los puntos convergentes y divergentes entre ellas y explorar el papel de las tecnologías de la información y la comunicación en estos proyectos. Los resultados de este estudio permitieron identificar un conjunto de proyectos diversificados de gran impacto para los profesionales que están en primera línea en la lucha contra COVID-19 y para la población más vulnerable, en particular los ancianos. Este estudio es especialmente relevante desde el punto de vista práctico al explorar la pertinencia de estas iniciativas, al poner de relieve la necesidad de un trabajo en colaboración y en equipos multidisciplinarios, y al fomentar su réplica a otros países.

Palabras clave: Humano2Humano, voluntariado, sociedad del conocimiento, tecnología, COVID-19 
$\mathbf{R}$ elations between business and consumers have been gradually changing. The Internet has given empowerment to customers by becoming a primary channel for contact with businesses (Acar \& Puntoni, 2016; Mohammad, 2020). Communication that used to be controlled by organizations is becoming increasingly bi-directional. Nowadays, there is not a clear and unequivocal differentiation about the way clients relate to the companies that used to guide their business strategies. The traditional concepts of Business2Business (B2B) and Business2Consumer (B2C) are blending together to reinvent organizations' planning for communication with their customers.

It is within this scenario that the Human2Human $(\mathrm{H} 2 \mathrm{H})$ business model that values the humanization of business relations emerges. This model considers that behind all negotiation there are people (Kramer, 2014). People become the center of the business activity in which strong relationships of trust are established. Moreover, Mansoor (2017) considers this approach has the potential to adjust quickly to shifting client needs. In this new $\mathrm{H} 2 \mathrm{H}$ business relationship model, companies do not look at their clients as revenue generated numbers, but as human beings with feelings and emotions (Padilla, 2019). In this sense, the company has to position itself differently, not only disclosing to its clients what is of self-interest but maintaining a bilateral relationship of transparency.

Consumers, with the wide diversity of information available to them, have become much more discerning and harder to reach (Bolton et al., 2018). Consequently, organizations need to readapt to understand the needs of the market, understand which messages are most relevant to each audience, and build this communication and assertive and informed way.

The COVID-19 pandemic has posed numerous challenges for organizations. Many companies had to temporarily close down, while others had to adapt their business model to meet the challenges posed by COVID19. Several companies have also sought to make their contribution by helping those on the front line in the fight against COVID-19. In parallel, several projects have also emerged to support society in the fight against social isolation, in the purchase of essential products, and in the demand for health services. These projects are characterized by having a strong $\mathrm{H} 2 \mathrm{H}$ component, in which humanized and close relationships are privileged. 


\section{Fernando Almeida - Human2Human in the Response to COVID-19}

This study seeks through five case studies to explore the role of these projects in the fight against COVID-19 in Portugal. It aims to analyze how the $\mathrm{H} 2 \mathrm{H}$ concept is explored in practice and to understand the relevance of these initiatives to the society. According to the Organization for Economic Co-operation and Development (OECD), Portugal is the country with the largest number of innovative projects in the fight against COVID-19, and therefore the analysis of these projects is relevant to understand their pertinence in combating this pandemic (OPSI, 2020). This study is structured as follows: Initially, a theoretical contextualization of the information and knowledge society, and the relevance of the Internet and digital technologies in contemporary society is carried out. After that, the methods adopted in this study are presented, also describing the process of data collection. It is also at this stage that the five case studies of this work are presented. Subsequently, the results of the study are presented and discussed according to the existing literature in each domain. Finally, the main conclusions of this study are summarized, and some future work points are suggested.

\section{Background}

Social and organizational developments have always sought to improve the lives of citizens in society in its multiple dimensions such as governance, productive and administrative systems, and technologies (Peláez \& Marcuello-Servós, 2018; Vargas-Hernandez, Noruzi \& Ali, 2011). People in their evolution have always sought to expand and develop their technologies (Heeks \& Stanforth, 2015). Therefore, it can be argued that the relationship between society and technology is a link of mutual dependence, where the citizen can benefit and enjoy all the services proposed by technology. In the context of the COVID-19 pandemic, solutions supported by emerging technologies can be a relevant ally of society and contribute to reducing people's isolation.

The impacts of technology on today's society are extremely wide-ranging and provide numerous daily benefits in social and business areas (Prado, 2019). In this way, it becomes essential to follow all the changes and be prepared to use the technologies according to their objectives. 


\section{The Information and Knowledge Society}

Technology has evolved at an unprecedented speed over the past few years and it is now present in many areas such as the economy, industry, culture, or entertainment. Volti (2017) states that today's society has become a technological society, as technologies are at the base and structure good and bad social changes and evolutions. Furthermore, technologies are proving to be determining factors of development (Coeurderoy, Nathalie \& Vas, 2014; Tidd \& Bessant, 2013).

We are experiencing a paradigm shift in all social domains, which fosters debate about relativity or loss of values (Levine, 2017). This is a transition to a society in which the boundaries are not yet perfectly defined, but where a progressively more globalized world is perceptible. Lindgren (2017) states this new paradigm is characterized by the shortening of distances and speed in the transmission of events, often by instantaneity, and the rapid movement of goods and people. This was particularly relevant in the spread of COVID19 at an astonishing rate from its emergence in China. In a short space of a few months, the virus had spread all over the world.

The paradigm shift we are currently experiencing appears under different names like information society, knowledge society, or postmodern society. This concept incorporates the main advances in information and communication technologies, microelectronics, and multimedia, whose great consequence is the dematerialization of productive spaces. However, technologies also cause some disadvantages. Ju and Pawlowski (2011) state people can become increasingly distant because the high communicative ease can become a barrier to the establishment of physical human relationships. Furthermore, children and young people may become increasingly dependent on technological means, and as a result, new risks regarding privacy and security arise (Kusyanti et al., 2017; Wisniewski, 2018). The issue of personal data privacy has been particularly relevant due to the emergence of mobile applications that track COVID-19. According to the OECD (2020), this has provoked a wide debate on the privacy of biometric personal data that could potentially be accessed by other individuals, companies, and government entities. 


\section{Fernando Almeida - Human2Human in the Response to COVID-19}

\section{The Role of the Internet and Digital Technologies}

Digital technologies have enabled a new dimension of products and services. Alongside this, access to information has changed the economic, political, and social landscape. However, the most important dimension of the computer or mobile phone is not about itself as an individual device, but the capacity they offer for networking (Antonucci, Ajrouch \& Manalei, 2017). Therefore, with the emergence and expansion of the Internet, ideas of freedom have come to revolutionize other areas like reading and networking. Citizens have become not only consumers of information but also producers of highly dynamic and interactive content (Dellaert, 2019; Lammi \& Pantzar, 2019).

Technology implies a transposition in the way individuals start to affect their social dialogues through the electronic environment, challenging territorial location, and postulating virtual reality in their daily lives. According to Muller and Peres (2019), a network-based social structure is a highly dynamic, open, and innovation-promoting system.

The development of new technologies in the IT sector has supplanted an increasingly competitive and specialized market (Henry-Nickie, Frimpong \& Sun, 2019). The use of the Internet among people and companies has become something indispensable nowadays. It is possible to have access to a vast network of information in real-time, and exchange data at any time. With the use of information technologies, services have been streamlined and facilitated (Mathiassen \& Pries-Heje, 2017). At the same time, there was a reduction in the workforce in areas that replaced human labor, but which opened new opportunities for the emergence of specialized occupations in the information and communication technologies field, such as software engineers, digital marketing professionals, blogs, or youtubers.

The Internet has made the citizen a potential communicating agent. Not only has the individual gained greater access to information, but he/she can also participate directly in it, giving opinions and interacting at the same time as receiving it. The interaction with people is no longer carried out in a massive way, but in an individual basis. Reddy (2017) stresses the need for organizations to maintain a 1:1 relationship with their customers. Through this approach, it becomes possible to provide differentiated real experiences using the Internet as a communication channel. 
One of the questions posed concerning the Internet is the formation of a virtual public space. For some critics with Gritsenko (2016), the Internet does not enable the objectification and consolidation of the general will, but only promotes the sharing of different points of view that can overlap with others from the dynamics of group interaction. However, as Hammond (2017) presents, the physical or geographical distance between people does not prevent the narrowing of relations in the social intent, through the virtual environment, and the interaction can occur without a fixed time and preestablished flow. The potential of the Internet has proved to be particularly useful in the context of teleworking and distance learning activities, where synchronous and asynchronous communication platforms have been used simultaneously (Morikawa, 2020).

In the face of this theoretical framework, it becomes clear that the valuation of technology must be carried out in a contextualized manner. The debate on the digital society is necessarily complex. The new information and communication technologies are not simply tools to be applied, but processes to be developed in society.

This study aims to explore how the technology-based solutions developed in Portugal in the context of the fight against COVID-19 have contributed to the implementation of the $\mathrm{H} 2 \mathrm{H}$ paradigm. Several initiatives are analyzed and their coverage and impact on society are discussed.

\section{Method}

In the social sciences in general, unlike in the natural and exact sciences, the phenomena are complex. Consequently, it is difficult to separate isolated and exclusive causes and motivations. These phenomena cannot be reproduced in the laboratory and subjected to control tests. They are always partial, depending on contexts, documents, observations, sensibilities, and perspectives. According to Yin (2017), qualitative methods enable an intensive analysis of data, both in amplitude and depth, which allows the researcher to look at the social units investigated as a whole.

In exploring the response to the challenges posed by COVID-19, it is necessary to understand and explore in-depth each of the initiatives launched by companies and the community. Each initiative has unique goals and challenges that become relevant to explore. To this end, this study adopts a 


\section{Fernando Almeida - Human2Human in the Response to COVID-19}

qualitative methodology through the realization of case studies in which convergent and divergent points between them can be explored. Furthermore, this approach allows us to carry out a micro-process analysis, through the study of individual and group actions. Queirós et al. (2017) state a case-study approach allows building an archive of descriptive material rich enough to enable subsequent reinterpretations.

However, the use of case studies also requires compliance with several key elements to ensure their robustness and reliability. Yin (2017) summarizes these elements from four perspectives: (i) construct validity; (ii) internal validity; (iii) external validity; (iv) reliability.

Multiple sources of evidence were used in the construct validity. The intention is to compare the evidences, but also to be sufficiently comprehensive to find new and distinctive evidences. This is a fundamental procedure in exploring the relevance of the $\mathrm{H} 2 \mathrm{H}$ paradigm, since each initiative has unique particularities that must be recognized and explored.

Internal validity was achieved through the selection of case studies that had their focus on meeting the challenges of COVID-19, and in which the $\mathrm{H} 2 \mathrm{H}$ paradigm was present. For this purpose, in each case study, it is addressed how its mission and approach articulates with the concept of $\mathrm{H} 2 \mathrm{H}$.

External validity has been accomplished through analytic generalization. Although it is recognized that the state of development of each initiative may change, motivated by both technological development and user feedback, the approach adopted allows its generalization to other applications that may be developed in the future.

Finally, the adoption of multiple data sources regarding each initiative allows us to explore a multidimensional view of the problem. With this, it is intended that the achieved results be sufficiently stable and in which the $\mathrm{H} 2 \mathrm{H}$ paradigm is analyzed in a similar way in an eventual replication process of this study.

\section{Data Collection}

The study was conducted between 6th and 22nd of April 2020. In the data collection, primary and secondary sources were used simultaneously. This was done to increase the degree of reliability in the interpretation of the study cases. The primary sources are the documents that generate an analysis 
for further development of information and serve to deepen the knowledge of a subject. They are those that contain original information. These elements were collected from the organizers of each initiative and their respective support community at operational and technical levels. The secondary sources are the result of studies previously carried out, representing the information processed and organized.

As primary sources of information were used the apps developed by each initiative, the documents provided by each entity, and the interactions through social networks (e.g., Facebook and Twitter). The interaction through social networks was particularly useful because it allowed to perceive the multiple perspectives on each project, enabling to collect feedback from both promoters and users. This is a key aspect of the $\mathrm{H} 2 \mathrm{H}$ paradigm, because on each side of this binomial we have humans, regardless of whether they are public or private organizations. This information was also relevant to have a more comprehensive view of the projects and to complete the primary sources of information.

Table 1.

Presentation of case studies

Name Description

Bombêuticos

Free home delivery of medicines, minimizing the risk of exposure and contamination.

CASES

Dissemination of various volunteer initiatives, allowing those who want to help and those who need help to identify the initiatives that best suit their profile and availability.

Preserve

Purchase vouchers in local commerce that can be used when they open again to the public.

SOS Neighbor

Provide people with the essential goods they need, preventing them from having to leave home.

Vent2life

Offering technical and specialist knowledge that is used in the repair of hospital equipment. 


\section{Fernando Almeida - Human2Human in the Response to COVID-19}

A total of five case studies were considered to combat COVID-19. Three criteria were fundamental in the choice of these case studies: (i) implementation of the $\mathrm{H} 2 \mathrm{H}$ paradigm; (ii) they were created within the framework of the response to COVID-19; and (iii) they are not aimed at financial profitability. Furthermore, and in the case of similar projects, it was decided to disclose the more general project scope. For example, in the case of having initiatives replicated at local level, only the national initiative grouping the information collected from each municipality was mentioned. Table 1 presents a brief description of these case studies.

\section{Ethical Requirements}

The data collected from the case studies were approved and supervised by the ethics committee of the researcher's university. Sensitive data were not used, and all data protected under the General Data Protection Regulation (EU GDPR) were anonymized.

\section{Results and Discussion}

In this section, each project is presented in detail and its relevance and impact are discussed considering the implementation of the $\mathrm{H} 2 \mathrm{H}$ paradigm and the challenges of responding to COVID-19.

\section{Bombêuticos}

"Bombêuticos" is an initiative that arose in Vila Nova de Gaia (North of Portugal) and was born from the joint movement between the São Paio pharmacy and the Carvalhos Voluntary Firemen. The mission of this project is to bring medicines home to those who need them most, especially the elderly population, at a time when Portugal is experiencing a public health crisis caused by COVID-19. The local fire service receives the order from each user and forwards it to the pharmacy. After receiving notification of the availability of material, it picks it up at the pharmacy and distributes it to each citizen's home.

This project essentially reaches a particularly vulnerable segment of the population that the mortality rate for individuals over 60 is three times 
higher than the general mortality rate (Kluge, 2020). In public and political discourse, it is widely referred to that an elderly person is a vulnerable person and therefore has to be protected. If the long-term isolation of the elderly population is essential for the protection of their physical health, Human Rights Watch (2020) notes that mitigation measures must be in place for lack of sociability and access to basic services. The response of volunteer firefighters in conjunction with pharmacies is a good example of the implementation of the $\mathrm{H} 2 \mathrm{H}$ paradigm, in which volunteering is a tool in the service of the most vulnerable population. Volunteer firefighters already have a history of service to the community. Their relevance in Portugal is unequivocal given the small number of professional fire services. Volunteer firefighters are the first line and, in many cases, the only line of civil protection in firefighting, disaster relief, or patient assistance (Lusa, 2018).

Deliveries are made by motorcycle, thus combining easy mobility with one of the passions of the founders of this initiative. The "Bombêuticos" ensure that on the same day or at the latest the day after the order is placed, the medicines are delivered to the recipient's home. This service has no additional cost and is done with complete security.

In recent weeks, the project has been extended to other pharmacies in northern Portugal. There are already about 30 adherent posts distributed in the area of Porto, Bragança, Vizela, Valpaços, among others. The objective of this organization is that this solidarity network can reach more pharmacies, which will be supported by the fire brigades of the area.

It is a project in which the $\mathrm{H} 2 \mathrm{H}$ paradigm is based on a model of proximity between volunteer firemen and the population. Although this proximity of the firefighters to the needs of their population is not new, this project allows to extend the capacity of the firefighters and its coverage.

\section{Cases}

An initiative promoted by the António Sérgio Cooperative for the Social Economy that aims to disseminate various voluntary initiatives that are being developed as part of the responses that are being dynamized to help those who suffer most from the impact of COVID-19. To respond to this new reality, several volunteer and solidarity actions are being carried out to 
support those most in need. The support initiatives are divided into two major groups: national initiatives and local initiatives.

Three projects at the national level stand out due to the relevance of their impact on the community. The initiative "\#cuidadetodos" aims at the national mobilization for volunteer work in institutions that support elderly people. The impact of this initiative is of great relevance given the vulnerabilities manifested by the elderly residences that have been a focus of the rapid spread of this virus (Gardner, States \& Bagley, 2020). Increasingly, and due to the infection, that has also been registered in health and social support professionals in these places, it is necessary to fill the need for human resources with experienced volunteers in the treatment of elderly people. Another initiative of great relevance was the strengthening of telehealth lines. At a time when the risk of contagion in the population is very high, the existence of telehealth lines that can meet these requests is essential to avoid contagion from health professionals and other patients (Horwitz, 2020). At the beginning of March 2020, the health line 24 in Portugal, which was responsible for filtering and routing patients at a distance, received less than 300 calls per day. However, the increase in demand in the weeks following the appearance of the first cases of COVID19 meant that there had to be a very significant increase in the number of health professionals providing this service. This project contributed significantly to the line being able to handle more than 18,000 calls per day by mid-April. Finally, another initiative of great relevance is promoted by the Order of the Doctors, in which an online survey was made available to collect the availability of health professionals in various areas, for collaboration with official health entities. Each entity will frame the volunteers in the teams, as necessary, and according to the profile and availability of each one. This initiative has received more than 3000 membership applications.

At the local level, the initiative is distributed among the 18 districts of mainland Portugal plus two autonomous archipelagos of Madeira and Azores. Table 2 provides some examples of the different types of initiatives that can be found. Many of the initiatives are common to several districts and most of them seek to attract volunteers to support the most deprived people, namely the elderly population. 
Table 2.

Local volunteer initiatives

Name District Description

Adopt a Grandpa Santarem

A group of young people from a local city created the Adopt a Grandpa project, using personal mobile phones. The initiative aims to combat loneliness, in which young volunteers call older people, thus making them company.

All for the Azores Azores

The movement raises funds to buy hospital supplies in the face of the Covid-19 pandemic. In articulation with the Regional Health Secretariat, it has created a network of contacts with various health professionals to validate the materials they intend to purchase.

CoFiq at home Madeira

A non-profit initiative, consisting mostly of young volunteers who help families order and deliver groceries, mail services, or go to pharmacies. Deliveries are made by volunteers, and the maximum amount of purchases is 50 euros.

Delivery of food Porto baskets

The initiative aims to ensure food for families in need.

Lighthouse Project Aveiro

This initiative was promoted by volunteers from the Local Volunteer Bank and teachers from the municipal program for the physical and mental balance of the senior population. They talk, listen, and register the most urgent needs of the elderly people of the municipality.

Protective suits Faro

Local authorities have acquired fabric for the making of protective suits and are looking for volunteers to make them.

Proximity support Lisbon

Twice a week, the elderly receives a phone call from the council and a home visit, if this is justified. Moreover, the council provides food support, delivery to the homes of needy families signposted, and makes the delivery and collection of clothes from community laundry users.

Sewing with the Leiria heart

The municipality asks for help to produce thousands of masks and distribute them to the 60 or so private charities in the municipality. To help, it is enough to have a sewing machine as the necessary material (fabric and elastic) is provided by the council.

$\begin{array}{ll}\text { Volunteer } & \text { Castelo } \\ \text { scholarship for } & \text { Branco }\end{array}$

Creation of a grant of volunteers to support the Portuguese Social Solidarity Institutions (IPSS) of the municipality. The registration signals the willingness to help the institutions that need, or will need, support. 


\section{Fernando Almeida - Human2Human in the Response to COVID-19}

This initiative is relevant in the context of the $\mathrm{H} 2 \mathrm{H}$ paradigm because it enables us to understand that more important than having large scale projects, is the existence of local initiatives that are close to their communities. The municipalities play an essential role because it is the administrative and political management entities that are closest to the populations.

\section{Preserve}

Much of the local trade because of COVID-19 is now closed. For micro companies, this situation causes strong constraints in their activity, and according to Von der Brelie (2020), there will have to be government support measures at the national and European levels to help these businesses. However, this help may come too late for many of these businesses. In this way, civil society also wants to help these small local businesses, as most of them will not be able to last more than 2 or 3 months without customers.

The Preserve project seeks to respond to this challenge by offering a web platform that allows the purchase of vouchers from local businesses. Vouchers have a validity period of 24 months. The money is transferred immediately to the account of the local store, although the service will only be carried out later. All payments are protected against fraud. Furthermore, there is a manual credibility check of all sites registered on the platform.

Purchasing vouchers is very easy and intuitive. The search is carried out by the user considering their geographical area and type of location (e.g. cafes, culture, restaurants, hotels, etc.). It is possible to know the location of each person through their GPS coordinates. The user selects the value of the voucher. Four pre-defined values are provided: $£ 20, £ 30, £ 40$, and $£ 50$. However, the user can enter any value between $\$ 10$ and $\$ 200$. After that, the user must indicate his contact email (necessary to send the voucher and send the purchase confirmation), the VAT (if he/she wishes to issue an invoice) and choose the payment method. Two payment methods are available: MBway and Multibanco. Each voucher contains a unique code, which corresponds specifically to the purchase made. The voucher refers to a single point of sale and it cannot be duplicated, edited, or sold. 
For the trader, this process is also quite simple. First of all, each entity must register on the platform and give some information about the establishment such as category, address, IBAN, etc. After registration has been completed, the information is transmitted to euPago, which is the payment partner. This entity makes verification of their data and requests more information, if necessary, to formalize the relationship. This is a legal requirement to comply with the Portuguese legislation. When the announcement is published the entity receives a notification. This whole process takes between 24 and 72 hours.

A key aspect considered in the development of this website was to offer high standards of user experience (UX). Offer greater user experience from the first contact, and the emotions of that moment must be included here as well, will lead to greater user satisfaction and, consequently, more likely to be their loyalty. A fundamental aspect of this project is that vouchers are purchased in a very intuitive way and that this positive experience is shared by users with their group of friends on social networks. Therefore, in the development of the website several UX best practices as recommended by Almeida and Monteiro (2017) and Bollini (2017) have been considered, which include easy access to content, an attractive design, the use of consistent standards throughout the interface, and the prevention of possible errors in data entry.

By mid-April 2020 this initiative already had more than 1000 registered establishments, more than 1500 vouchers sold and more than 30 thousand euros raised for local commerce. This is an initiative that can make a decisive contribution to the local population's favorite establishments being able to maintain their activity, even if they are not open to the public. This initiative is particularly important at an early stage when the financial means to support these establishments are unclear and are slow to arrive. It is also an initiative that fosters the $\mathrm{H} 2 \mathrm{H}$ paradigm through direct support between consumers and entrepreneurs. This proximity that occurs in local commerce can continue to exist even if it is physically distant from that commercial establishment. Furthermore, as Hammond (2017) advocates, this is a great example in which the interaction between individuals can occur outside the typical business hours of each establishment. This help is now available 24 hours a day, 7 days a week. 


\section{Fernando Almeida - Human2Human in the Response to COVID-19}

\section{SOS Neighbor}

SOS Neighbor is a project that has brought together more than a hundred specialists from various areas and zones of the country. The goal is to organize a support network for groups at risk who are currently in social isolation. In the first phase, it was fundamental to signal the risk groups of each region and organize a network of distribution, through volunteers who register online. This initiative aims to bring to these people the essential goods they need, preventing them from leaving their homes and consequently being more exposed.

In order to organize all volunteers in a single database, all applications are made by filling out an online form. Not all people can be volunteers since because of the current risk situation it is necessary to consider some exclusions, namely the chronically ill, individuals with suspicious symptoms of COVID-19, and under 18 years old or over 60 years old. Although information about the volunteer's district is requested, it is expected that the volunteer will act only within his/her municipality and as close to each person as possible. This is to follow the recommendations of the government to minimize the displacement of people. Furthermore, and even though it is not a criterion for exclusion, the promoters of the initiative ask for volunteers living with people belonging to risk groups to have extra care when they arrive home.

The volunteer assumes the following duties: (i) receive the request for assistance, after notification of the coordinator of your municipality; (ii) make the purchase (of essential goods or medicines with and without a prescription); (iii) deliver the request to their home; and (iv) receive payment of the request (if he/she receive this indication). The volunteer may work full-time or part-time. However, if the number of volunteers allows it, and in order to limit the emergence of transmission chains, it stipulates that the volunteer should not collaborate for more than 7 consecutive days without a 14-day quarantine interval.

SOS Neighbor defines the following risk groups: (i) elderly people over 65; (ii) chronically ill (e.g., hypertensive, diabetic, heart problems); (iii) single parents with children under 12 years of age in their care; and (iv) patients in compulsory quarantine. Information about the person, their location, and the goods needed are required in requests for help. Six 
categories of products are envisaged: (i) food; (ii) fresh food; (iii) cleaning products; (iv) hygiene products; (v) first aid; and (vi) medicines.

This initiative demonstrates the great proximity between people in need of help and volunteers. This proximity is fundamental for the correct implementation of the $\mathrm{H} 2 \mathrm{H}$ paradigm. Although not everyone can volunteer, these restrictions are widely accepted by society. Above all, the health of those involved comes first. This is markedly a project in which the Internet has facilitated the approximation between those in need and those who are available to help. The initiative has volunteers spread throughout the country with the aim of helping these groups at risk, aware of all the care needed at this time to avoid contagion.

\section{Vent2life}

This initiative was launched on 24 March 2020 by a group of volunteers and emerged due to a problem that became more apparent in this critical period of response to Covid-19. Many hospitals report the existence of hospital equipment that is down due to breakdowns and, without technical intervention, could not be used. At a time when hospitals are experiencing severe restrictions on the availability of medical equipment as reported by Livingston, Desai and Berkwits (2020), this project is a valuable help in minimizing the number of unavailable equipment. All this equipment is necessary for the sustainability of patient care.

According to the founders of this initiative, the goal is to repair at least 200 broken or inactive ventilators that are stored in several hospitals in Portugal. This is a project that brings together a very large and multidisciplinary community in the scientific and technological areas. Joining forces is fundamental to the success of this initiative since the solutions proposed for each problem have to be customized.

The project's workflow from a conceptual point of view is quite simple. In the first phase, the hospitals report the equipment problems. After that, the problems are reported in the collaborative platform. These requests are forwarded according to the technicians' profile. Each of the experts with competence in the area receives a notification of a new incident has been entered into the system. The teams are dynamically built through the members' acceptance responses. The fault repair process is highly 


\section{Fernando Almeida - Human2Human in the Response to COVID-19}

collaborative, in which the commitment and strong dedication of all is fundamental. This typically multidisciplinary team is responsible for identifying solutions to the problems reported. Finally, the hospital approves the repair and concludes the process.

Not being a project aimed at society, its impact on the $\mathrm{H} 2 \mathrm{H}$ dimension is also remarkable. This support is directed at hospitals and medical personnel who are on the front line in the fight against COVID-19. Furthermore, another key factor for the success of this initiative is the involvement of professionals with highly specialized technical and scientific knowledge. With this, networks of knowledge can be created. According to Phelps, Heidi and Wadhwa (2012), knowledge networks provide a better use of information and knowledge generated in the internal and external environment, helping decision-making processes. This project calls for collaborative intelligence as a way to bring distinctive results to hospitals.

\section{Conclusions}

The $\mathrm{H} 2 \mathrm{H}$ paradigm values people as human beings and their desire to be included in the search for solutions in the fight against COVID-19. People need in this period of high uncertainty to be part of something greater than themselves. Throughout this study, the applicability of this concept was demonstrated through five case studies. These case studies correspond to non-profit initiatives promoted jointly by a broad community of volunteers in multidisciplinary fields. These projects seek to bring volunteers closer to people in need of help and allow them to support various projects such as the delivery of medicines and essential goods, support for the repair of hospital equipment, and support for local commerce.

This study offers mainly practical contributions by exploring the relevance of these projects and knowing how they work. It aims to present in what way various public and private agents and society, in general, have come together in the search for solutions to mitigate the effects of COVID19 in Portugal. Furthermore, this work intends to contribute to similar initiatives to be replicated in other countries. Some limitations can be pointed out in this study. Firstly, it is not possible to present all the projects in this area, and some have been chosen for their effect given their relevance in the community. Another fundamental element is that these projects are in 
permanent change and updating and, therefore, it is always fundamental to consider this limitation when analyzing the results. As future work, it is intended to explore how volunteer initiatives can be sustainable in the long term after the COVID-19 period since it is desirable that the $\mathrm{H} 2 \mathrm{H}$ paradigm can continue to grow and become economically and socially sustainable.

\section{References}

Acar, O. A., \& Puntoni, S. (2016). Customer Empowerment in the Digital Age. Journal of Advertising Research, 56(1), 4-8. doi: 10.2501/JAR2016-007

Almeida, F., \& Monteiro, J. A. (2017). Approaches and Principles for UX Web Experiences: A Case Study Approach. International Journal of Information Technology and Web Engineering (IJITWE), 12(2), 4965. doi: 10.4018/IJITWE.2017040103

Antonucci, T. C., Ajrouch, K. J., \& Manalei, J. A. (2017). Social Relations and Technology: Continuity, Context, and Change. Innovation in Aging, 1(3), 1-9. doi: 10.1093/geroni/igx029

Bollini, L. (2017). Beautiful interfaces. From user experience to user interface design. The Design Journal, 20(1), 589-601. doi: 10.1080/14606925.2017.1352649

Bolton, R., McColl-Kennedy, J., Cheung, L., Gallan, A., Orsingher, C., Witell, L., \& Zaki, M. (2018). Customer experience challenges: bringing together digital, physical and social realms. Journal of Service Management, 29(5), 776-808. doi: 10.1108/JOSM-04-20180113

Coeurderoy, R., Nathalie, G., \& Vas, A. (2014). Explaining factors affecting technological change adoption. Management Decision, 52(6), 10821100. doi: 10.1108/MD-10-2013-0540

Dellaert, B. (2019). The consumer production journey: marketing to consumers as co-producers in the sharing economy. Journal of the Academy of Marketing Science, 47, 238-254. doi: 10.1007/s11747018-0607-4 
Gardner, W., States, D., \& Bagley, N. (2020). The Coronavirus and the Risks to the Elderly in Long-Term Care. Journal of Aging \& Social Policy, In Press. doi: 10.1080/08959420.2020.1750543

Gritsenko, V. (2016). Interaction on Online Forums and Group

Communication: A Case Study of an IT Support Community.

Procedia - Social and Behavioral Sciences, 236, 14-24. doi:

10.1016/j.sbspro.2016.12.004

Hammond, M. (2017). Online collaboration and cooperation: The recurring importance of evidence, rationale and viability. Education and Information Technologies, 22, 1005-1024. doi: 10.1007/s10639-0169469-x

Heeks, R., \& Stanforth, C. (2015). Technological change in developing countries: opening the black box of process using actor-network theory. Development Studies Research, 2(1), 33-50. doi: 10.1080/21665095.2015.1026610

Henry-Nickie, M., Frimpong, K., \& Sun, H. (2019). Trends in the Information Technology sector. Retrieved from Brookings website: https://www.brookings.edu/

Horwitz, L. (2020). The Benefits of Telehealth Step into the Breach Wrought by COVID-19. Retrieved from IOT World Today website:

https://www.iotworldtoday.com/

Human Rights Watch (2020). Rights Risks to Older People in COVID-19 Response. Retrieved from Human Rights Watch website:

https://www.hrw.org/

Ju, B., \& Pawlowski, S. (2011). Exploring the barriers and challenges of information and communication technology use in distributed research today: A ranking-type Delphi study. Proceedings of the American Society for Information Science and Technology, 48(1), 1-9. doi: 10.1002/meet.2011.14504801101

Kluge, H. (2020). Statement - Older people are at highest risk from COVID19, but all must act to prevent community spread. Retrieved from

World Health Organization website: http://www.euro.who.int

Kramer, B. (2014). There is No B2B or B2C: It's Human to Human. London, UK: Substantium.

Kusyanti, A., Puspitasari, D. R., Catherina, H., \& Sari, Y. (2017).

Information Privacy Concerns on Teens as Facebook Users in 
Indonesia. Procedia Computer Science, 124, 632-638. doi: 10.1016/j.procs.2017.12.199

Lammi, M., \& Pantzar, M. (2019). The data economy: How technological change has altered the role of the citizen-consumer. Technology in Society, 59, 1-8. doi: 10.1016/j.techsoc.2019.101157

Levine, S. (2017). Where Have All Our Values Gone? Psychology Today. Retrieved from: https://www.psychologytoday.com/

Lindgren, S. (2017). Digital Media and Society. Thousand Oaks, California:

SAGE Publications.

Livingston, E., Desai, A., \& Berkwits, M. (2020). Sourcing Personal

Protective Equipment During the COVID-19 Pandemic. JAMA. doi:

10.1001/jama.2020.5317

Lusa (2018). Ministro diz que bombeiros são "grande força da estrutura da protecção civil". Publico. Retrieved from: https://www.publico.pt/

Mansoor, H. (2017). B2B to H2H: A New Thinking On Customer Experience Management. Retrieved from: https://customerthink.com/b2b-to-h2ha-new-thinking-on-customer-experience-management/

Mathiassen, L., \& Pries-Heje, J. (2017). Business agility and diffusion of information technology. European Journal of Information Systems, 15(2), 116-119. doi: 10.1057/palgrave.ejis.3000610

Mohammad, A. (2020). The effect of customer empowerment and customer engagement on marketing performance: the mediating effect of brand community membership. Business: Theory and Practice, 21(1), 30-38. doi: $10.3846 /$ btp.2020.11617

Morikawa, M. (2020). COVID-19, teleworking, and productivity. Retrieved from the VOX portal website: https://voxeu.org/

Muller, E., \& Peres, R. (2019). The effect of social networks structure on innovation performance: A review and directions for research.

International Journal of Research in Marketing, 36(1), 3-19. doi: 10.1016/j.ijresmar.2018.05.003

OECD (2020). Tracking and tracing COVID: Protecting privacy and data while using apps and biometrics. Retrieved from OECD website: http://www.oecd.org

OPSI (2020). OPSI COVID-19 Innovative Response Tracker. Retrieved from the Observatory of Public Sector Innovation website: https://oecd-opsi.org/ 
Padilla, L. (2019). There Is No More B2B Or B2C. It's H2H: Human to Human. New York: Independently Published.

Peláez, A. L., \& Marcuello-Servós, C. (2018). e-Social work and digital society: re-conceptualizing approaches, practices and technologies. European Journal of Social Work, 21(6), 801-803. doi: 10.1080/13691457.2018.1520475

Phelps, C., Heidi, R., \& Wadhwa, A. (2012). Knowledge, Networks, and Knowledge Networks: A Review and Research Agenda. Journal of Management, 38(4), 1115-1166. doi: 10.1177/0149206311432640

Prado, C. G. (2019). How Technology Is Changing Human Behavior: Issues and Benefits. Santa Barbara, California: Praeger.

Queirós, A., Faria, D., \& Almeida, F. (2017). Strengths and Limitations of Qualitative and Quantitative Research Methods. European Journal of Education Studies, 3(9), 369-387. doi: 10.5281/zenodo.887089

Reddy, K. P. (2017). H2H: How the "Human to Human" Marketing Approach Reveals Who We Are in Business and in Life. Medium. Retrieved from: https://medium.com/

Tidd, J., \& Bessant, J. R. (2013). Managing Innovation: Integrating Technological, Market and Organizational Change. Hoboken, New Jersey: Wiley.

Vargas-Hernandez, J., Noruzi, M. R., \& Ali, I. F. (2011). What is Policy, Social Policy and Social Policy Changing? International Journal of Business and Social Science, 2(10), 287-291.

Volti, R. (2017). Society and Technological Change. New York: Worth Publishers.

Von der Brelie, H., Beslija, A., Kiss, G., \& Vodenitcharov, D. (2020, April

3). Covid-19: What are the consequences for small and medium enterprises across Europe? Euronews. Retrieved from:

https://www.euronews.com/

Wisniewski, P. (2018). The Privacy Paradox of Adolescent Online Safety: A

Matter of Risk Prevention or Risk Resilience? IEEE Security \&

Privacy, 16(2), 86-90. doi: 10.1109/MSP.2018.1870874

Yin, R. (2017). Case Study Research and Applications: Design and Methods. Thousand Oaks, California: SAGE Publications. 
Fernando Almeida is Professor and Affiliated Researcher of the School of Science and Technology at the University of Porto, INESC TEC \& ISPGAYA, Portugal

Contact Address: almd@fe.up.pt 